\title{
Sex differences in experiences of multiple traumas and mental health problems in the UK Biobank cohort
}

\author{
Emma Yapp ${ }^{1} \cdot$ Tom Booth $^{2} \cdot$ Katrina Davis $^{1,3} \cdot$ Jonathan Coleman $^{1,3} \cdot$ Louise M. Howard $^{1} \cdot$ Gerome Breen $^{1,3}$. \\ Stephani L. Hatch ${ }^{1,4} \cdot$ Matthew Hotopf $^{1,3} \cdot$ Siân Oram $^{1}$ (D)
}

Received: 31 May 2020 / Accepted: 7 April 2021

(c) The Author(s) 2021

\begin{abstract}
Purpose Experiences of reported trauma are common and are associated with a range of mental health problems. Sex differences in how reported traumas are experienced over the life course in relation to mental health require further exploration. Methods 157,358 participants contributed data for the UK Biobank Mental Health Questionnaire (MHQ). Stratified Latent Class Analysis (LCA) was used to analyse combinations of reported traumatic experiences in males and females separately, and associations with mental health.

Results In females, five trauma classes were identified: a low-risk class (58.6\%), a childhood trauma class (13.5\%), an intimate partner violence class (12.9\%), a sexual violence class (9.1\%), and a high-risk class (5.9\%). In males, a three-class solution was preferred: a low-risk class (72.6\%), a physical and emotional trauma class (21.9\%), and a sexual violence class (5.5\%). In comparison to the low-risk class in each sex, all trauma classes were associated with increased odds of current depression, anxiety, and hazardous/harmful alcohol use after adjustment for covariates. The high-risk class in females and the sexual violence class in males produced significantly increased odds for recent psychotic experiences.

Conclusion There are sex differences in how reported traumatic experiences co-occur across a lifespan, with females at the greatest risk. However, reporting either sexual violence or multiple types of trauma was associated with increased odds of mental health problems for both males and females. Findings emphasise the public mental health importance of identifying and responding to both men and women's experiences of trauma, including sexual violence.
\end{abstract}

Keywords Violence $\cdot$ Gender-based violence $\cdot$ Mental health $\cdot$ Women's health

This article belongs to the Topical Collection Violence and Women's Mental Health.

Siân Oram

sian.oram@kcl.ac.uk

1 Institute of Psychology, Psychiatry and Neuroscience, King's College London, London, UK

2 Department of Psychology, University of Edinburgh, Edinburgh, UK

3 South London and Maudsley NHS Foundation Trust, NIHR Biomedical Research Centre, De Crespigny Park, Denmark Hill, London, UK

4 ESRC Centre for Society and Mental Health, King's College London, London, UK

\section{Introduction}

A traumatic event is defined as exposure to actual or threatened death, serious injury or sexual violence through direct experience or witnessing in the Diagnostic and Statistical Manual for Mental Disorders 5th edition. Experiences of both violence and trauma are highly prevalent in the general population. Global estimates indicate that up to $36 \%$ of people have experienced childhood maltreatment [1], though there are sex differences: $18 \%$ of girls report childhood sexual abuse, compared to $8 \%$ of boys [1], and $47 \%$ of boys ${ }^{1}$ have been in a physical fight in the past year compared

\footnotetext{
${ }^{1}$ Herein, we use "sex" to refer to the sex assigned to people at birth, and "gender" to describe self-identification as a man, woman, or nonbinary/genderqueer person. This discussion is inherently limited by the literature, which frequently subscribes to binary representations (and conflations) of both sex and gender. The content of this paper focuses on sex as a binary variable, as this was the only measure used in the UK Biobank data.
} 
to $26 \%$ of girls [2]. Sex differences persist for experiences of violence in adulthood: $26 \%$ of women and $15 \%$ of men report domestic violence and abuse in adulthood [3]. Certain traumatic experiences are likely to co-occur; for example, people who experience one form of childhood maltreatment are likely to experience another, because they are often living with their perpetrator [4]. This continues across the life course. According to stress proliferation theory [5], there are both direct relationships between traumatic experiences (e.g. types of childhood maltreatment) and indirect ones. For example, being a victim of violence or abuse may contribute to the onset of mental health problems, which in turn renders individuals vulnerable to further violence or abuse [6].

Experiences of violence and reported trauma are associated with mental disorders across the diagnostic spectrum and are highly prevalent among people with psychiatric diagnoses [7]. However, questions remain over how to conceptualise combinations of sex differences in traumatic experiences in relation to mental health. While some research emphasises that mental health service users have experienced multiple forms of abuse [8], there is little consensus over how multiple victimisation differs between the sexes, as this literature typically conducts analyses solely on women [9], or the population as a whole [10]. This gap in the literature raises important questions about how such combinations of experiences differ between the sexes, and how they should be quantified in relation to mental health research and clinical practice.

Previous research has been dominated by additive approaches in which each additional traumatic experience is assumed to increase the odds of developing mental health problems to the same extent. This method has been criticised [11] for its assumption that all traumas contribute equally to the development of mental health problems. Some researchers have therefore begun to use variable-centred approaches, such as factor analysis, to examine how traumatic events group together [12]. Factor analytic methods have also been criticised, as they assume that the studied population all experience traumas in the same ways [13]; studying the "effect", rather than the "cause" [14].

Person-centred approaches, such as Latent Class Analysis (LCA), in which the individual is the unit of analysis, offer an alternative to these methods. LCA seeks to identify groups of individuals who report exposure to combinations of trauma. LCA has been applied to diverse arrays of traumatic experiences [13], including both interpersonal and non-interpersonal traumas. These studies tend to establish classes characterised by experiences of domestic and sexual violence in women, and classes of non-interpersonal or non-sexual trauma in men [10]. However, direct comparisons between adult men and women within the same cohort are highly limited, and most findings tend to be established within single-sex samples [10]. Compared to classes characterised by a low risk for traumatic experiences, individuals in groups with a higher risk of traumatic experiences have higher odds of experiencing mental health problems [13].

Experiences of violence and trauma are gendered [15, 16], yet there is a paucity of work examining whether stratification of data by sex/gender leads to different patterns of exposure for men and women, and different impacts on mental health [13]. This study, therefore, uses LCA to examine sex differences in exposure to a wide range of interpersonal and other traumas and in association with mental health problems. It uses data from the UK Biobank Mental Health Questionnaire (MHQ)-a large cohort of more than 150,000 adults in the United Kingdom - on lifetime trauma and adversity, including types of traumas more commonly experienced by women (such as domestic and sexual violence). The inclusion of these items is particularly important, as a measurement of domestic and sexual violence has been limited in a large cohort and psychiatric morbidity surveys, meaning that few datasets permit direct comparison between men and women's experiences of trauma over the life course in relation to mental health [17]. We aim to establish and characterise the sex differences in experiences of multiple reported traumas in the UK Biobank.

\section{Methods}

\section{Sample}

The UK Biobank is a large population-based cohort study of people recruited via assessment centres across the UK between 2006 and 2010. Postal invitations were sent to $9,238,453$ individuals registered with the UK's National Health Services who were aged 40-69 and lived within 25 miles of one of 22 assessment centres throughout the UK. Overall, 503,317 individuals initially consented to participate in the UK Biobank-a participation rate of 5.5\%. There is significant evidence of a "healthy volunteer" bias within the UK Biobank; participants have higher socio-economic status, better education and health compared to the general population. This cohort is therefore not representative of the UK general population, and neither are the data produced by the subset of participants who participated in the MHQ [18]. Individuals who participated in the MHQ were more likely to: be female, have attended assessment centres in Greater London and the South West of England, have higher educational attainment, not currently smoke, have fewer hospital diagnoses, and have a family history of dementia or severe depression compared to those who did not participate [19]. Consent was obtained for future longitudinal follow-up and linkage with routinely collected health-related data. The MHQ was administered online to participants as part of this 
follow-up in 2016-17 [20]. The MHQ was developed to be short (20-30 min total), with an emphasis on depression and the use of established measures such as the Composite International Diagnostic Interview Short Form (CIDISF), and the Childhood Trauma Screener [21]. The MHQ was incorporated into the UK Biobank web platform as a questionnaire about "thoughts and feelings"; a hyperlinked email was then sent to consenting participants who had provided an email address. Of the 339,229 participants invited to complete the MHQ, 157,366 (46.3\%) did so [20]. Several individuals subsequently withdrew their consent for their data to be used; 157,358 people are included in our analyses.

\section{Measures}

\section{Mental health}

Current depression was measured using the Patient Health Questionnaire (PHQ-9); patients who endorsed more than five symptoms as present on "more than half the days" (and "thoughts that you would be better off dead, or of hurting yourself in some way" on at least "several days") including at least one core symptom (depressed mood and loss of interest) were classified as currently experiencing depression (equivalent to DSM Major Depressive Disorder) [22]. Current anxiety was measured using the seven-item Generalised Anxiety Disorder scale (GAD-7) using the established cutoff point of a score of ten or more [23]. Current hazardous/ harmful alcohol use was measured using the Alcohol Use Disorders Identification Test, using the established cut-off: a score of eight or more [24]. Recent psychotic experiences were determined using an abridged version of the psychosis module of the CIDI, determined by whether participants reported psychotic experiences (visual hallucinations; auditory hallucinations; delusions of reference; persecutory delusions) within the last 12 months [25].

\section{Trauma and adversity}

Adverse childhood experiences were measured using the Childhood Trauma Screener [21], a shortened version of the Childhood Trauma Questionnaire [26]; items asked participants about traumatic experiences while "growing up"; items were endorsed on a five-point Likert scale ("never true", "rarely true", "sometimes true", "often", "very often true"), and dichotomised. A short checklist with binary answers ("yes, "no") was used to identify lifetime traumatic experiences as defined by the Diagnostic and Statistical Manual of Mental Disorders [27, 28], and a checklist for measuring adverse experiences (e.g. intimate partner violence) occurring in adulthood (age 16 years and above) was devised by the study team; items on intimate partner violence (IPV) were adapted from the Crime Survey for England and Wales
[29]. Two additional items about relationship and financial insecurity were included such that the structure of this questionnaire would be comparable to the Childhood Trauma Screener. For all items relating to experiences of trauma, participants were provided with the opportunity to decline to answer. Altogether, these measures produced 16 items (see Table 1).

\section{Socio-demographics and socio-economics}

The socio-demographic indicators used in the analysis included: sex, age, ethnicity, migrant status, loneliness, and social isolation. Ethnicity and sex were self-reported, and the ethnicity variable indicated identification with either: Black (Caribbean, African, any other Black background), Asian (Indian, Pakistani, Bangladeshi, any other Asian background), Chinese, Mixed (White and Black Caribbean, White and Black African, any other Mixed background), Other, or White ethnicities (White British, White Irish, any other White background); on account of the low prevalence of non-White ethnicities, ethnicity was coded as a binary variable. Migrant status was determined by whether participants were born in the UK, and loneliness was self-reported. Social isolation was a binary variable determined by participants' social and community activities; participants were deemed isolated if they were living alone, were visited by family and/or friends less than once a week, and did not attend any regular social activities. The socio-economic indicators used included: Townsend Deprivation Score, education, and household income. Townsend Deprivation Material Scores were based on census data; each participant was assigned a score corresponding to the output area of their residential postcode (least deprived $<-2.00$, average -2.00 to 1.99 , or most deprived: $\geq 2.00$ ) [18]. Educational attainment was classified by qualification. Participants reporting degree level; A Levels or equivalent; or secondary school or equivalent (including O levels, CSEs, HNDs, HNCs and NVQs) qualifications were classified as such. Participants reporting none of the above, but the attainment of "other" qualifications (e.g. nursing, teaching) were classified as "other"; and those reporting none of the above were categorised as such. Household income was classified as: under $£ 18,000 ; £ 18,000-£ 30,000 ; £ 30,000-£ 52,000$; $£ 52,000-£ 100,000$; and more than $£ 100,000$.

\section{Statistical analysis}

The prevalence of the 16 individual adverse life experiences was calculated both in the overall sample and for males and females separately. Latent class structures were explored in both males and females individually and the sample as a whole, to ensure that the sex-stratified LCA provided the best solution [30]. 
Table 1 Prevalence of individual traumatic experiences

\begin{tabular}{|c|c|c|c|c|c|c|c|}
\hline Item & Question (and item coding) & $\begin{array}{l}\text { Whole } \\
\text { sample } \\
(\%)\end{array}$ & Missing (\%) & Males (\%) & Missing (\%) & Females $(\%)$ & Missing (\%) \\
\hline \multicolumn{8}{|l|}{ Childhood trauma screener } \\
\hline Emotional childhood neglect & $\begin{array}{l}\text { When I was growing up I felt } \\
\text { loved (less than "often") }\end{array}$ & 22.4 & 0.4 & 21.6 & 0.4 & 23.0 & 0.4 \\
\hline Emotional childhood abuse & $\begin{array}{l}\text { When I was growing up people } \\
\text { in my family hit me so hard } \\
\text { that it left me with bruises or } \\
\text { marks (more than "never") }\end{array}$ & 15.6 & 0.3 & 12.7 & 0.2 & 17.8 & 0.3 \\
\hline Physical childhood abuse & $\begin{array}{l}\text { When I was growing up I felt } \\
\text { like someone in my family } \\
\text { hated me (more than "never") }\end{array}$ & 18.9 & 0.2 & 21.1 & 0.2 & 17.3 & 0.3 \\
\hline Physical childhood neglect & $\begin{array}{l}\text { When I was growing up some- } \\
\text { one molested me sexually } \\
\text { (more than "never") }\end{array}$ & 16.3 & 0.7 & 15.2 & 0.6 & 17.2 & 0.8 \\
\hline Sexual childhood abuse & $\begin{array}{l}\text { When I was growing up there } \\
\text { was someone to take me to } \\
\text { the doctor if I needed it (less } \\
\text { than "very often") }\end{array}$ & 8.7 & 1.2 & 5.8 & 0.6 & 10.9 & 1.6 \\
\hline \multicolumn{8}{|c|}{ Adulthood ( $\geq 16$ years) questionnaire } \\
\hline Relationship insecurity & $\begin{array}{l}\text { Since I was sixteen, I have } \\
\text { been in a confiding relation- } \\
\text { ship (less than "often") }\end{array}$ & 31.2 & 2.6 & 30.8 & 2.0 & 31.6 & 3.1 \\
\hline $\begin{array}{l}\text { Physical intimate partner } \\
\text { violence }\end{array}$ & $\begin{array}{l}\text { Since I was sixteen, a partner } \\
\text { or ex-partner deliberately } \\
\text { hit me or used violence in } \\
\text { any other way (more than } \\
\text { "never") }\end{array}$ & 12.8 & 0.3 & 8.0 & 0.2 & 16.4 & 0.4 \\
\hline $\begin{array}{l}\text { Psychological intimate part- } \\
\text { ner violence }\end{array}$ & $\begin{array}{l}\text { Since I was sixteen, a partner } \\
\text { or ex-partner repeatedly } \\
\text { belittled me to the extent that } \\
\text { I felt worthless (more than } \\
\text { "never") }\end{array}$ & 24.0 & 0.3 & 15.7 & 0.2 & 30.2 & 0.4 \\
\hline $\begin{array}{l}\text { Sexual intimate partner } \\
\text { violence }\end{array}$ & $\begin{array}{l}\text { Since I was sixteen, a partner } \\
\text { or ex-partner sexually } \\
\text { interfered with me, or forced } \\
\text { me to have sex against my } \\
\text { wishes (more than "never") }\end{array}$ & 5.8 & 0.3 & 0.8 & 0.2 & 9.5 & 0.4 \\
\hline Financial insecurity & $\begin{array}{l}\text { Since I was sixteen, there was } \\
\text { money to pay the rent or } \\
\text { mortgage when I needed it } \\
\text { (less than "very often") }\end{array}$ & 14.5 & 1.6 & 12.8 & 1.5 & 15.8 & 1.6 \\
\hline \multicolumn{8}{|c|}{ Lifetime traumatic experiences (childhood or adulthood) } \\
\hline Serious accident & $\begin{array}{l}\text { In your life have you been in } \\
\text { a serious accident that you } \\
\text { believed to be life-threaten- } \\
\text { ing at the time ("yes") }\end{array}$ & 9.8 & 0.1 & 13.5 & 0.1 & 7.0 & 0.1 \\
\hline Witness death & $\begin{array}{l}\text { In your life have you witnessed } \\
\text { a sudden violent death (e.g. } \\
\text { murder, suicide, aftermath of } \\
\text { an accident) ("yes") }\end{array}$ & 13.5 & 0.2 & 19.3 & 0.2 & 9.0 & 0.2 \\
\hline Serious illness & $\begin{array}{l}\text { In your life have you been } \\
\text { diagnosed with a life-threat- } \\
\text { ening illness ("yes") }\end{array}$ & 16.3 & 0.4 & 17.8 & 0.3 & 15.1 & 0.5 \\
\hline
\end{tabular}


Table 1 (continued)

\begin{tabular}{|c|c|c|c|c|c|c|c|}
\hline Item & Question (and item coding) & $\begin{array}{l}\text { Whole } \\
\text { sample } \\
(\%)\end{array}$ & Missing (\%) & Males (\%) & Missing (\%) & Females $(\%)$ & Missing (\%) \\
\hline Experienced war & $\begin{array}{l}\text { In your life have you been } \\
\text { involved in combat or } \\
\text { exposed to a war-zone (either } \\
\text { in the military or as a civil- } \\
\text { ian) ("yes") }\end{array}$ & 3.6 & 0.1 & 6.2 & 0.2 & 1.6 & 0.1 \\
\hline Sexual violence ever & $\begin{array}{l}\text { In your life have you been a } \\
\text { victim of a sexual assault, } \\
\text { whether by a stranger or } \\
\text { someone you knew ("yes") }\end{array}$ & 14.8 & 1.3 & 7.6 & 0.6 & 20.3 & 1.8 \\
\hline Physically violent crime & $\begin{array}{l}\text { In your life have you been } \\
\text { attacked, mugged, robbed, or } \\
\text { been the victim of a physi- } \\
\text { cally violent crime ("yes") }\end{array}$ & 19.0 & 0.2 & 25.0 & 0.1 & 19.0 & 0.2 \\
\hline
\end{tabular}

The fit of up to six models (one-class through to six) was assessed, as a systematic review of person-centred analyses of traumatic items indicated that all included studies identified solutions in this range [13]. Models were evaluated using the Bayesian Information Criterion (BIC) [31], the sample size adjusted BIC (ssaBIC) [32], Pearson's likelihood ratio chi-square $\left(\mathrm{G}^{2}\right)$ statistic [33], the consistent Akaike Information Criterion (cAIC) [34], and the identification of coherent and conceptually meaningful solutions. Goodness of fit in LCA models is indicated by lower values for cAIC, BIC, and ssaBIC. The accuracy of classification of classes was determined by inspection of average posterior probabilities of class membership (provided in Tables S1 and S2), and entropy measures, with higher values (ranging from 0 to 1) indicating better classification [35]. Thirty random sets of starting values were used to avoid converging on local maxima [33].

Final class solutions were then used to calculate individuals' class membership using modal class assignment; that is, assigning individuals to the class for which the estimated probability is the largest [30]. Class solutions were regressed on all covariates, to explore the characteristics of individuals in each class; latent class variables were dummy coded for both males and females. Current or recent mental health problems were regressed on class membership using logistic regressions; both adjusted and unadjusted models are presented. Adjusted regression models controlled for age, ethnicity (White vs non), Townsend Deprivation Score, educational attainment, household income, migrant status, loneliness, and social isolation. All analyses were conducted in $\mathrm{R}$ statistical computing environment [36] version 3.5.1, and LCA was conducted using the poLCA package [33]. Missing data were handled using available case analysis, apart from during the LCA, as poLCA can accommodate missing values by initially excluding missing data on any indicator variables to calculate prior probabilities, and then updating these probabilities using as many indicator variables as are observed for each individual after calculating posteriors [33].

\section{Results}

Data from 157,358 participants were included in our analyses: 68,261 males and 89,097 females (see Table S3). The largest proportion of participants in both sexes were aged 65-74 (42.5\% females, $47.2 \%$ males), of White ethnicity ( $96.7 \%$ females, $96.6 \%$ males), living in areas characterised as least deprived by the Townsend Deprivation Index $(55.6 \%$ females, 57.4\% males), and earning $£ 30,000-£ 52,000$ as a household ( $24.9 \%$ females, $27.4 \%$ males). Proportions were consistent across the sexes, and the demographic details of this sample have been discussed in detail elsewhere [20].

\section{Prevalence of trauma and adversity}

The prevalence of reported trauma and adversity is presented in Table 1. For both males and females, the most common adverse experience was relationship insecurity in adulthood ( $\geq 16$ years), reported by $30.8 \%$ and $31.6 \%$, respectively. The second most common adverse experience was, for males, physically violent crime ever $(25.0 \%)$ and for females, psychological abuse from an intimate partner in adulthood $(31.2 \%)$. The prevalence rates for sexual childhood abuse, sexual intimate partner violence, and sexual violence ever all differ. Although there is the conceptual overlap between these items, overlap between positive responses was relatively low, and thus these items are treated as independent from each other in ensuing analyses. Missing data were between 0.1 and $3.1 \%$ across items. 


\section{Determining latent classes}

Table 2 presents the goodness of fit statistics for sex-stratified latent class models. The optimum solution for the whole sample was determined as the four-class solution (see Table S4), yet optimum class solutions differed within males and females separately, and thus results are reported for these groups individually only.

In females, the BIC, ssaBIC, and cAIC all decreased with the introduction of additional classes. However, the entropy was highest for the four-class model; the four and five class models were, therefore, considered the best candidates for the optimal solution, and the average posterior probabilities were relatively comparable across both solutions (see Table S2), but the five class solution was preferred on the basis of its conceptual coherence (see Figs. $\mathrm{S} 1$ and S2); model-predicted probabilities are displayed in Table 3. Class $1(N=10,533,12.9 \%)$ indicated high probabilities of items relating to physical and psychological intimate partner violence and was thus labelled the intimate partner violence class. Class $2(N=55,063,58.6 \%)$ indicated low probabilities across all adverse items and was labelled the low-risk class. Class $3(N=5051,5.9 \%)$ was characterised by generally high probabilities across adverse items and was labelled the high-risk class. Class $4(N=7644,9.1 \%)$ exhibited high probabilities of the sexual violence and abuse items (sexual assault ever and childhood sexual abuse) and was labelled the sexual violence class. Class $5(N=10,806,13.5 \%)$ was characterised by relatively high probabilities of experiencing physical abuse and emotional abuse and neglect in childhood, plus relationship insecurity in adulthood; this was labelled the childhood trauma class.

In males, the BIC, ssaBIC, and cAIC similarly all decreased with the addition of more classes. However, the entropy measure indicated that the best candidates for the optimal model were the three and four class models. The three-class model was again chosen on the basis of conceptual coherence (see Figs. S3 and S4) and displayed marginally more consistent average posterior probabilities than the four-class solution (see Table S3); modelpredicted probabilities are displayed in Table 3. Class 1 $(N=3589,5.5 \%)$ was characterised by moderate strength probabilities across most items, with a particularly high probability of sexual violence ever and childhood sexual abuse; this was labelled the sexual violence class. Class 2 $(N=13,311,21.9 \%)$ exhibited medium-strength probabilities across several items and a low probability of sexual violence; this was labelled the physical and emotional trauma class. Class $3(N=51,361,72.6 \%)$ displayed low probabilities across all adverse items and was labelled the low-risk class.

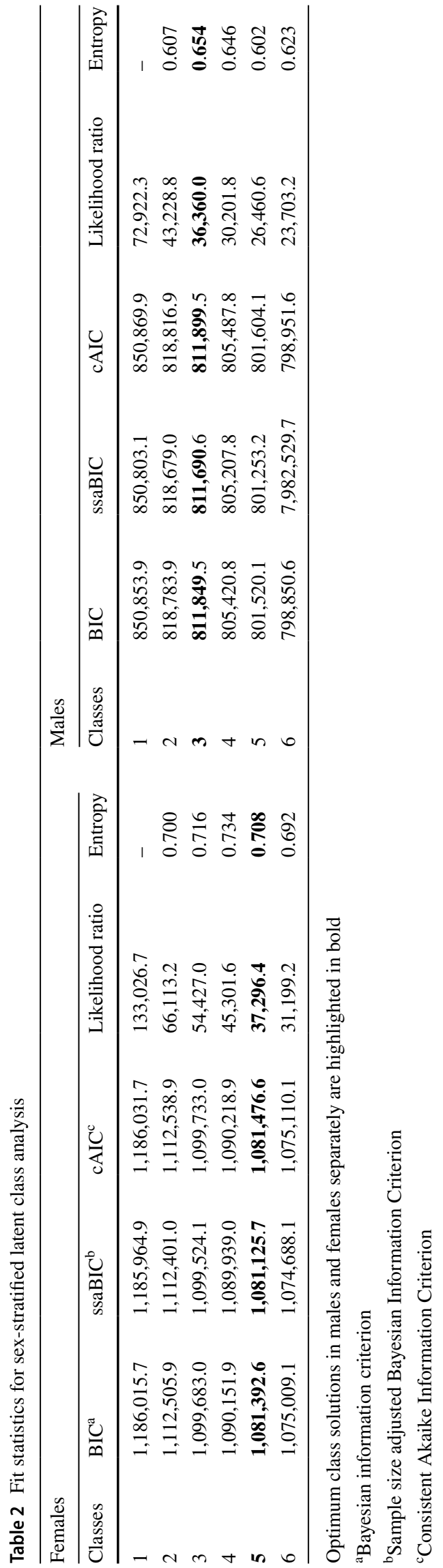


Table 3 Model-predicted probabilities for 3 class solution in males and 5 class solution in females

\begin{tabular}{|c|c|c|c|c|c|c|c|c|}
\hline & \multicolumn{3}{|l|}{ Males } & \multicolumn{5}{|l|}{ Females } \\
\hline & Low risk & $\begin{array}{l}\text { Physical and } \\
\text { emotional } \\
\text { trauma }\end{array}$ & Sexual violence & Low risk & Sexual violence & $\begin{array}{l}\text { Intimate } \\
\text { partner } \\
\text { violence }\end{array}$ & Child abuse & High risk \\
\hline \multicolumn{9}{|l|}{ Childhood trauma and adversity } \\
\hline $\begin{array}{l}\text { Emotional childhood } \\
\text { neglect }\end{array}$ & 0.09 & 0.56 & 0.39 & 0.05 & 0.29 & 0.17 & 0.75 & 0.85 \\
\hline Physical childhood abuse & 0.11 & 0.51 & 0.42 & 0.05 & 0.27 & 0.16 & 0.41 & 0.69 \\
\hline Emotional childhood abuse & 0.03 & 0.42 & 0.29 & 0.04 & 0.24 & 0.14 & 0.53 & 0.80 \\
\hline Sexual childhood abuse & 0.01 & 0.03 & 0.76 & 0.01 & 0.63 & 0.08 & 0.05 & 0.49 \\
\hline Physical childhood neglect & 0.10 & 0.31 & 0.22 & 0.10 & 0.16 & 0.11 & 0.39 & 0.54 \\
\hline \multicolumn{9}{|c|}{ Adulthood ( $\geq 16$ years) trauma and adversity } \\
\hline Relationship insecurity & 0.26 & 0.49 & 0.35 & 0.24 & 0.28 & 0.38 & 0.52 & 0.65 \\
\hline $\begin{array}{l}\text { Physical intimate partner } \\
\text { violence }\end{array}$ & 0.03 & 0.21 & 0.19 & 0.03 & 0.09 & 0.68 & 0.09 & 0.68 \\
\hline $\begin{array}{l}\text { Psychological intimate } \\
\text { partner violence }\end{array}$ & 0.08 & 0.37 & 0.31 & 0.12 & 0.23 & 0.91 & 0.32 & 0.87 \\
\hline $\begin{array}{l}\text { Sexual intimate partner } \\
\text { violence }\end{array}$ & 0.00 & 0.02 & 0.05 & 0.01 & 0.08 & 0.37 & 0.03 & 0.53 \\
\hline Financial insecurity & 0.09 & 0.25 & 0.16 & 0.10 & 0.12 & 0.26 & 0.23 & 0.45 \\
\hline \multicolumn{9}{|c|}{ Lifetime traumatic experiences (childhood or adulthood) } \\
\hline Serious accident & 0.10 & 0.24 & 0.23 & 0.04 & 0.12 & 0.10 & 0.07 & 0.18 \\
\hline Witness death & 0.15 & 0.30 & 0.30 & 0.06 & 0.15 & 0.11 & 0.09 & 0.21 \\
\hline Serious illness & 0.16 & 0.21 & 0.24 & 0.13 & 0.17 & 0.17 & 0.17 & 0.22 \\
\hline Experienced war & 0.04 & 0.11 & 0.11 & 0.01 & 0.03 & 0.02 & 0.02 & 0.04 \\
\hline Sexual violence ever & 0.02 & 0.04 & 0.94 & 0.05 & 0.92 & 0.30 & 0.08 & 0.75 \\
\hline Physically violent crime & 0.19 & 0.40 & 0.43 & 0.10 & 0.23 & 0.21 & 0.14 & 0.37 \\
\hline
\end{tabular}

\section{Associations of trauma classes with socio-demographic and socio-economic variables}

Class solutions were dummy coded using the low-risk category as the reference category for both sexes. Logistic regressions were used to investigate the socio-demographic and socio-economic characteristics of individuals in each class.

Compared to the low-risk group, females in lower household income brackets, living in more deprived TDI areas, and who were classified as lonely were more likely to be members of trauma classes (see Table 4); females who identified as non-White were more likely to be members of the sexual violence, childhood trauma, and high-risk groups; females born outside of the UK had increased odds of being in the childhood trauma group; and females who were socially isolated were more likely to be members of the intimate partner violence, childhood trauma, and high-risk groups. The sexual violence and intimate partner violence classes were characterised by marginally higher education compared to the low-risk group, whereas the childhood trauma class reflected lower education compared to low risk, although the effect sizes were extremely small. Compared to the low-risk group, males who were in lower household income brackets, living in more deprived areas, who were lonely, and who were socially isolated were more likely to be members of the trauma classes. Males who identified as non-White, and who were born outside of the UK were additionally more likely to be in the sexual violence class compared to the low-risk class. Males with higher educational status were less likely to be in the class characterised by sexual violence.

\section{Associations with current or recent mental health}

As shown in Table 5, in females, membership of trauma classes was significantly associated with depression, anxiety, and hazardous/harmful alcohol use compared to the lowrisk class in both unadjusted and adjusted analyses. Only the high-risk class was associated with psychotic experiences. In males, both classes were associated with depression, anxiety, and hazardous/harmful alcohol use compared to the low-risk class in both unadjusted and adjusted analyses. In adjusted 
Table 4 Associations between socio-demographic and socio-economic variables and trauma classes compared to the low risk class

\begin{tabular}{|c|c|c|c|c|c|c|}
\hline & \multicolumn{4}{|l|}{ Females } & \multicolumn{2}{|l|}{ Males } \\
\hline & $\begin{array}{l}\text { Sexual violence } \\
\text { vs Low risk: OR } \\
(95 \% \mathrm{CI})\end{array}$ & $\begin{array}{l}\text { Intimate partner } \\
\text { violence vs Low } \\
\text { risk: OR }(95 \% \mathrm{CI})\end{array}$ & $\begin{array}{l}\text { Childhood trauma } \\
\text { vs Low risk: OR } \\
(95 \% \text { CI })\end{array}$ & $\begin{array}{l}\text { High risk vs Low } \\
\text { risk: OR }(95 \% \mathrm{CI})\end{array}$ & $\begin{array}{l}\text { Physical and } \\
\text { emotional trauma } \\
\text { vs Low risk: OR } \\
(95 \% \mathrm{CI})\end{array}$ & $\begin{array}{l}\text { Sexual violence vs } \\
\text { Low risk: OR ( } 95 \% \\
\text { CI) }\end{array}$ \\
\hline Age & $1.0(1.0-1.0)$ & $1.0(1.0-1.0)$ & $1.0(1.0-1.0)$ & $0.9(0.9-1.0)$ & $1.0(1.0-1.0)$ & $1.0(1.0-1.0)$ \\
\hline Ethnicity $^{\mathrm{a}}$ & $1.4(1.2-1.6)$ & $1.1(0.9-1.3)$ & $1.8(1.5-2.0)$ & $2.1(1.8-2.5)$ & $1.6(1.4-1.8)$ & $1.3(1.1-1.7)$ \\
\hline Migrant status ${ }^{\mathrm{b}}$ & $1.2(1.0-1.3)$ & $1.0(0.9-1.1)$ & $1.2(1.1-1.3)$ & $1.1(1.0-1.2)$ & $1.2(1.1-1.3)$ & $1.2(1.0-1.4)$ \\
\hline \multicolumn{7}{|l|}{$\mathrm{TDI}^{\mathrm{c}}$} \\
\hline Average & $1.3(1.2-1.3)$ & $1.3(1.3-1.4)$ & $1.2(1.1-1.2)$ & $1.5(1.4-1.7)$ & $1.3(1.2-1.3)$ & $1.4(1.3-1.5)$ \\
\hline Most deprived & $1.6(1.5-1.7)$ & $1.8(1.6-1.9)$ & $1.3(1.2-1.4)$ & $2.4(2.2-2.6)$ & $1.6(1.5-1.7)$ & $2.1(1.9-2.3)$ \\
\hline \multicolumn{7}{|l|}{ Education $^{\mathrm{d}}$} \\
\hline Other & $1.4(1.2-1.7)$ & $1.1(0.9-1.2)$ & $1.0(0.9-1.1)$ & $1.0(0.8-1.2)$ & $0.9(0.8-1.0)$ & $1.4(1.1-1.7)$ \\
\hline GCSE & $1.2(1.1-1.4)$ & $1.3(1.2-1.5)$ & $0.9(0.8-1.0)$ & $1.1(0.9-1.3)$ & $0.9(0.8-0.9)$ & $1.0(0.9-1.2)$ \\
\hline A Level & $1.3(1.1-1.5)$ & $1.4(1.2-1.6)$ & $0.9(0.8-0.9)$ & $1.1(0.9-1.3)$ & $0.9(0.8-0.9)$ & $1.1(0.9-1.3)$ \\
\hline Degree level & $1.5(1.3-1.7)$ & $1.3(1.2-1.5)$ & $0.9(0.8-1.0)$ & $1.2(1.0-1.4)$ & $0.7(0.7-0.8)$ & $1.1(0.9-1.2)$ \\
\hline \multicolumn{7}{|l|}{ Household income } \\
\hline $\begin{array}{l}£ 18,000- \\
£ 30,000^{\mathrm{e}}\end{array}$ & $0.9(0.8-1.0)$ & $0.7(0.7-0.8)$ & $0.8(0.8-0.9)$ & $0.6(0.5-0.6)$ & $0.8(0.7-0.8)$ & $0.8(0.7-1.0)$ \\
\hline$£ 30,000-£ 52,000$ & $0.9(0.8-1.0)$ & $0.6(0.6-0.7)$ & $0.8(0.7-0.8)$ & $0.4(0.4-0.5)$ & $0.8(0.7-0.8)$ & $0.8(0.7-0.9)$ \\
\hline $\begin{array}{l}£ 52,000- \\
£ 100,000\end{array}$ & $0.9(0.8-0.9)$ & $0.5(0.5-0.6)$ & $0.7(0.6-0.7)$ & $0.3(0.3-0.4)$ & $0.7(0.6-0.7)$ & $0.8(0.7-0.9)$ \\
\hline Over $£ 100,000$ & $0.9(0.8-1.0)$ & $0.5(0.4-0.5)$ & $0.6(0.5-0.6)$ & $0.3(0.3-0.3)$ & $0.6(0.6-0.7)$ & $0.8(0.7-1.0)$ \\
\hline Loneliness $^{\mathrm{f}}$ & $1.5(1.3-1.8)$ & $1.8(1.6-2.0)$ & $2.7(2.5-3.0)$ & $3.6(3.1-4.1)$ & $2.3(2.1-2.5)$ & $1.9(1.7-2.3)$ \\
\hline Social isolation ${ }^{\mathrm{g}}$ & $1.1(1.0-1.2)$ & $1.2(1.1-1.3)$ & $1.5(1.4-1.6)$ & $1.6(1.5-1.8)$ & $1.4(1.3-1.5)$ & $1.3(1.1-1.4)$ \\
\hline Model N & 52,675 & 55,152 & 55,081 & 50,351 & 57,658 & 59,124 \\
\hline
\end{tabular}

${ }^{a}$ Ethnicity was coded as a binary variable: $0=$ White, $1=$ non-White

${ }^{\mathrm{b}}$ Migrant status was coded as a binary variable: $0=$ non-migrant, $1=$ migrant

${ }^{\mathrm{c}}$ Tertiles were derived from postcode areas; categories used least deprived TDI as the reference category

dEach education level used "none of the above" as the reference category

${ }^{\mathrm{e}}$ All household income categories used under $£ 18,000$ as the reference category

${ }^{\mathrm{f}}$ Self-reported

'Determined by participants' self-reported social and community activities, and whether they lived alone; coded as a binary variable 0

analyses, only the sexual violence class was associated with psychotic experiences.

\section{Discussion}

This study constitutes one of the largest latent class analyses (LCA) identifying how combinations of interpersonal and non-interpersonal trauma are experienced by males and females over the life course. Our analysis demonstrates differences in the patterning of reported traumatic experiences between males and females, and shows that more females were members of classes characterised by multiple traumas $(41 \%)$ than were males $(27 \%)$. Among both males and females, membership of classes characterised by multiple traumas was associated with increased odds of mental health problems, with the highest odds among females in the highrisk group.

The prevalence of individual adverse life events was consistent with other large samples and population-based data, for example the Adverse Childhood Experiences (ACE) study [4] (as well as child maltreatment research conducted more recently in the UK context $[37,38]$ ), the Crime Survey for England and Wales [39], and the World Mental Health surveys [40]. This is despite the UK Biobank MHQ participants being unrepresentative of the general population (being predominantly White, having higher socio-economic status, better education, and better health than the UK average) [18]. Higher prevalence of psychological intimate partner violence was found for the UK Biobank MHQ (30\% in females, $16 \%$ in males) when compared to surveys conducted with similar questions in England and Wales [41] 
Table 5 Unadjusted and adjusted odds ratios (ORs) and confidence intervals for current and recent mental health outcomes by latent class compared to the low-risk class

\begin{tabular}{|c|c|c|c|c|c|c|c|c|}
\hline & $\begin{array}{l}\text { Unadj } \\
\text { Depression }\end{array}$ & $\mathrm{Adj}^{\mathrm{a}}$ & $\begin{array}{l}\text { Unadj } \\
\text { Anxiety }\end{array}$ & Adj & $\begin{array}{l}\text { Unadj } \\
\text { Alcohol }\end{array}$ & Adj & $\begin{array}{l}\text { Unadj } \\
\text { Psychotic } \\
\text { experiences }\end{array}$ & Adj \\
\hline \multicolumn{9}{|l|}{ Females } \\
\hline $\begin{array}{l}\text { Sexual vio- } \\
\text { lence }\end{array}$ & $3.1(2.6-3.7)$ & $2.5(2.0-3.0)$ & $2.7(2.2-3.2)$ & $2.4(2.0-2.9)$ & $1.8(1.7-1.9)$ & $1.6(1.5-1.7)$ & $1.3(0.9-1.8)$ & $1.1(0.8-1.6)$ \\
\hline $\begin{array}{l}\text { Intimate part- } \\
\text { ner violence }\end{array}$ & $4.0(3.5-4.6)$ & $2.9(2.5-3.4)$ & $3.2(2.8-3.8)$ & $2.7(2.3-3.2)$ & $1.9(1.8-2.0)$ & $1.8(1.6-1.9)$ & $1.1(0.8-1.6)$ & $1.0(0.7-1.4)$ \\
\hline $\begin{array}{l}\text { Childhood } \\
\text { trauma }\end{array}$ & $4.8(4.2-5.5)$ & $3.8(3.3-4.5)$ & $4.7(4.1-5.3)$ & $4.0(3.4-4.6)$ & $1.3(1.2-1.4)$ & $1.3(1.2-1.4)$ & $1.4(1.0-1.9)$ & $1.2(0.8-1.7)$ \\
\hline High risk & $\begin{array}{l}14.8(12.9- \\
16.8)\end{array}$ & $8.9(7.6-10.4)$ & $\begin{array}{l}14.1(12.4- \\
16.2)\end{array}$ & $9.2(7.9-10.9)$ & $2.0(1.8-2.1)$ & $1.9(1.7-2.1)$ & $2.8(2.1-3.6)$ & $2.0(1.5-2.7)$ \\
\hline \multicolumn{9}{|l|}{ Males } \\
\hline $\begin{array}{l}\text { Physical and } \\
\text { emotional } \\
\text { trauma }\end{array}$ & $5.9(5.1-6.7)$ & $4.1(3.5-4.7)$ & $5.4(4.7-6.2)$ & $4.0(3.4-4.7)$ & $1.3(1.3-1.4)$ & $1.3(1.3-1.4)$ & $1.5(1.2-1.9)$ & $1.2(1.0-1.7)$ \\
\hline $\begin{array}{l}\text { Sexual vio- } \\
\text { lence }\end{array}$ & $6.5(5.4-7.8)$ & $5.0(4.0-6.1)$ & $6.0(4.9-7.4)$ & $4.8(3.8-6.0)$ & $1.4(1.3-1.6)$ & $1.4(1.3-1.6)$ & $2.2(1.6-3.0)$ & $1.9(1.4-2.6)$ \\
\hline
\end{tabular}

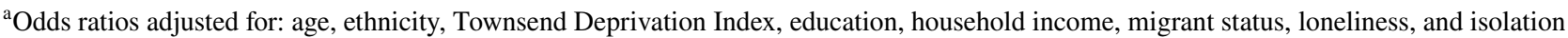

(18\% in females, $8 \%$ in males); these may be attributable to differences in questionnaire response options [42].

Our analysis grouped male participants into a low-risk class, a physical and emotional trauma class, and a sexual violence class. Notably, our study established a class of males characterised by sexual violence, the trauma profile of which differed from that of the female sexual violence class, as it was characterised by additional moderate risks of physical victimisation in childhood and adulthood; a similar finding was recently established in a large $(N=34,653)$ sexstratified LCA of childhood maltreatment [43]. This group of males may have been obscured in non-stratified LCAs [13]. While experiences of sexual violence are more prevalent in females, little exploration has been previously conducted of how male experiences of sexual violence cluster with other traumas. An estimated 3\% of males report sexual violence before the age of 16 in England and Wales [37], and 4\% thereafter [44]. Males who are sexually victimised in childhood are also significantly more likely to be physically and sexually victimised in adulthood [45]. The male sexual violence class identified by our analysis experienced increased odds of all current or recent mental health problems; a finding also established in the aforementioned stratified LCA of child maltreatment [43]. This group is worthy of further investigation, in terms of understanding male experiences of sexual violence in combination with other traumas, causal pathways and moderators of mental health outcomes, and investigation of optimal service responses and therapeutic interventions.

Females were grouped into five classes: a low-risk class, a sexual violence class, an intimate partner violence class, a childhood trauma class, and a high-risk class; similar findings have been established previously [9]. While previous research conducted in the UK context has and shown that women were more likely to be members of classes characterised by a high risk of violence and abuse [46], our analysis indicates that the high-risk class in this cohort is unique to females. While the male sexual violence class had increased risk of physical victimisation, the high-risk class indicated that $5.9 \%$ females multiply experience childhood trauma, sexual violence, and partner violence.

Being a member of all classes characterised by reporting trauma increased a person's odds of currently experiencing depression, anxiety, and hazardous/harmful alcohol use compared to the low-risk classes in this analysis. These findings fit with other psychiatric literature demonstrating high rates of adverse life experiences among people experiencing anxiety and depression [7], as well as research scrutinising the relationship between adverse life experiences and alcohol use [47]. The high-risk class in females had the strongest associations with all recent mental health problems, and only the high-risk class in females and the sexual violence class in males were associated with recent psychotic experiences. This finding contrasts other work that shows associations between experiences of childhood trauma [48], sexual violence $[9,10]$, non-interpersonal traumas [10] and psychotic experiences. This may be due to the unrepresentativeness of both the UK Biobank and the constituent MHQ [18, 19], as the recruitment strategies for this cohort may have been likely to exclude people with recent psychotic experiences. Nevertheless, our findings underscore the enduring 
psychiatric impact of multiple traumas including sexual violence and have important implications.

\section{Implications}

Our findings demonstrate that there are distinct classes of males and females experiencing violence and trauma, and that members of these classes experience increased odds of mental health problems. Early identification of experiences of violence and abuse in health services may help mitigate the enduring effects of violence. In mental health services, recent policy and guidance have largely focused on identifying experiences of childhood sexual abuse [49] and domestic violence and abuse [50] on account of their high prevalence amongst mental health service users $[8,51$, 52]. Our findings emphasise the importance of identifying other experiences of trauma; in particular, experiences of multiple victimisation and sexual violence. Referrals and clinical pathways differ across experiences of trauma and violence, and identification methods are often focused on particular cohorts of people [50]. People who use mental health services often complain of traumatic experiences not being identified sooner, and the impact of this on treatment [53]. Taking a universal approach to experiences of adversity amongst mental health service users may therefore enable earlier identification of trauma, and consequently improve treatment outcomes. Although a significantly greater proportion of females are subjected to sexual violence than males in the general population [44], experiences of sexual violence are highly prevalent among both male and female mental health service users [51]. Despite this, mental health services rarely conduct routine enquiry into adulthood sexual violence [54]. Enquiry into childhood physical abuse may be similarly productive, as this too is under-identified by mental health services [52], and our findings indicate a small group of males who experience both childhood physical abuse and lifetime sexual violence.

\section{Strengths and limitations}

To our knowledge, this is the largest study to conduct a sexstratified latent class analysis on experiences of violence and trauma across the life course and to analyse the relationship between class membership and current or recent mental health. This cohort provided rich data on trauma experienced from childhood to older adulthood, as well as robust measures of mental health, and a diverse array of sociodemographic and socioeconomic variables, that allowed us to interrogate how trauma exposure is shaped by life experience.

There are several important limitations to note. Participants in the UK Biobank and MHQ are not representative of the general population $[18,19]$. The majority of participants were White, and recruitment to the cohort was consistent with the 'healthy volunteer' effect, such that participants tended to be in better health than the general population [18]. However, generalisable associations with risk factors can be obtained in non-representative samples such as these, provided sufficiently large numbers of people with a range of exposures are included [55]. In addition, many of the items used to assess traumatic experiences may suffer from recall bias, and had either not been validated in this population, or were scored using different methods elsewhere in the literature [21]. In addition, the questions about relationship and financial security may have been interpreted in such a way that they are not indicative of trauma. The measurement of sex was binary and precluded the assessment of gendered experiences of trauma. There is also an issue of temporality, as many of the lifetime adverse experiences either overlap with each other or do not specify when the trauma occurred.

While the entropy measures indicated moderate separation between classes, these statistics were lower than some other work using latent class analysis to analyse traumatic experiences [56]. This is likely because other research has focused on more homogeneous groups of traumatic items-for example, conducting LCA of childhood maltreatment $[43,56]$, as types of childhood maltreatment often co-occur [4]. The heterogeneity of traumatic experiences studied in our research will bear on class separation, as we examined both interpersonal and non-interpersonal traumas; our entropy measures were comparable to other work examining similar ranges of traumatic experiences [13].

It should also be noted that the traumatic items represented in the UK Biobank MHQ cohort, and therefore in this analysis, are by no means exhaustive. Members of the team involved in developing the MHQ had an interest in experiences of violence against women, including domestic and sexual violence (authors SO and LMH). Several trauma items included in the MHQ measured experiences of violence that are more prevalent in women than men, and this is reflected in the class solutions identified; had the MHQ focused on traumatic experiences more commonly experienced by men, the class solutions would likely have differed. For example, other studies have asked more detailed questions probing experiences of threats, physical violence, and the witnessing of violence or death, all of which were more likely to be experienced by men [57]. These items, as well as ones pertaining to the death of loved ones, and the witnessing of trauma, should be investigated further with regard to associations with mental health. Experiences of trauma and violence may further vary across countries [58]. The groups of latent classes identified here may therefore not be representative of the general population, but rather represent groups of individuals specific to this sample, in this country. The analysis of associations between sociodemographic variables and class membership, therefore, 
provides important information about who is in each class, and this should be taken into account when interpreting the findings.

\section{Conclusions}

This study established that males and females in the UK Biobank MHQ Cohort experience different patterns of trauma and adversity over their lifetime, with females more likely to experience multiple types of trauma. Among both males and females, experiencing multiple types of trauma was associated with current and recent mental health problems, with odds highest among classes characterised by multiple victimisation and sexual violence. Longitudinal and sex-disaggregated evidence is needed to further unpack the relationship between experiences of trauma, adversity, and mental health over the life course among males and females.

Supplementary Information The online version contains supplementary material available at https://doi.org/10.1007/s00127-021-02092-y.

Funding LMH is supported by a National Institute for Health Research (NIHR) Research Professorship (NIHR-RP-R3-12-011). SLH is part supported by the ESRC Centre for Society and Mental Health at King's College London (ESRC Reference: ES/S012567/1). This paper represents independent research part-funded by the National Institute for Health Research (NIHR) Biomedical Research Centre at South London and Maudsley NHS Foundation Trust and King's College London.

Availability of data and material UK Biobank data is open-access subject to the usual access procedures (www.ukbiobank.ac.uk); the data used in this analysis are from an approved extension to application 16,577 (G. Breen).

Code availability R code is freely available on the King's College London data repository: https://doi.org/10.18742/RDM01-727.

\section{Declarations}

Conflict of interest The authors declare that they have no conflict of interest.

Ethics approval The North West-Haydock Research Ethics Committee provided approval for the UK Biobank and the MHQ: 11/NW/0382.

Consent to participate Participants provided written consent and are free to withdraw at any time.

Open Access This article is licensed under a Creative Commons Attribution 4.0 International License, which permits use, sharing, adaptation, distribution and reproduction in any medium or format, as long as you give appropriate credit to the original author(s) and the source, provide a link to the Creative Commons licence, and indicate if changes were made. The images or other third party material in this article are included in the article's Creative Commons licence, unless indicated otherwise in a credit line to the material. If material is not included in the article's Creative Commons licence and your intended use is not permitted by statutory regulation or exceeds the permitted use, you will need to obtain permission directly from the copyright holder. To view a copy of this licence, visit http://creativecommons.org/licenses/by/4.0/.

\section{References}

1. World Health Organization (2014) Global status report on violence prevention 2014. WHO, Geneva

2. World Health Organization (2015) Preventing youth violence: an overview of the evidence. WHO, Geneva

3. Office for National Statistics (2018) Domestic abuse: findings from the Crime Survey for England and Wales: year ending March 2017. ONS, London

4. Felitti VJ, Anda RF, Nordenberg D, Williamson DF, Spitz AM, Edwards V, Koss MP, Marks JS (1998) Relationship of childhood abuse and household dysfunction to many of the leading causes of death in adults: the Adverse Childhood Experiences (ACE) Study. Am J Prev Med 14(4):245-258

5. Pearlin LI, Aneshensel CS, LeBlanc AJ (1997) The forms and mechanisms of stress proliferation: the case of AIDS caregivers. J Health Soc Behav 38(3):223-236

6. Devries KM, Mak JY, Bacchus LJ, Child JC, Falder G, Petzold M, Astbury J, Watts CH (2013) Intimate partner violence and incident depressive symptoms and suicide attempts: a systematic review of longitudinal studies. PLoS Med 10(5):e1001439

7. Trevillion K, Oram S, Feder G, Howard LM (2012) Experiences of domestic violence and mental disorders: a systematic review and meta-analysis. PLoS ONE. https://doi.org/10.1371/journal. pone. 0051740

8. Anderson F, Howard L, Dean K, Moran P, Khalifeh H (2016) Childhood maltreatment and adulthood domestic and sexual violence victimisation among people with severe mental illness. Soc Psychiatry Psychiatr Epidemiol 51(7):961-970

9. Shevlin M, O’Neill T, Houston JE, Read J, Bentall RP, Murphy J (2013) Patterns of lifetime female victimisation and psychotic experiences: a study based on the UK Adult Psychiatric Morbidity Survey 2007. Soc Psychiatry Psychiatr Epidemiol 48(1):15-24

10. Houston JE, Shevlin M, Adamson G, Murphy J (2011) A person-centred approach to modelling population experiences of trauma and mental illness. Soc Psychiatry Psychiatr Epidemiol 46(2):149-157

11. Gebauer S, Moore R, Salas J (2019) All traumas are not created equal. JAMA Pediatr 173(4):398-399

12. Silove D, Brooks R, Steel Bateman C, Steel Z, Amaral FC, RodgerSoosay JI (2010) Social and trauma-related pathways leading to psychological distress and functional limitations four years after the humanitarian emergency in Timor-Leste. J Trauma Stress 23(1):151-160

13. O'Donnell ML, Schaefer I, Varker T, Kartal D, Forbes D, Bryant RA, Silove D, Creamer M, McFarlane A, Malhi G (2017) A systematic review of person-centered approaches to investigating patterns of trauma exposure. Clin Psychol Rev 57:208-225

14. Bollen K, Lennox R (1991) Conventional wisdom on measurement: a structural equation perspective. Psychol Bull 110(2):305

15. Walby S, Towers $\mathbf{J}$ (2018) Untangling the concept of coercive control: theorizing domestic violent crime. Criminol Crim Just 18(1):7-28

16. Ansara DL, Hindin MJ (2010) Exploring gender differences in the patterns of intimate partner violence in Canada: a latent class approach. J Epidemiol Community Health 64(10):849-854

17. Walby S, Towers JS (2017) Measuring violence to end violence: mainstreaming gender. J Gender-Based Violence 1(1):11-31 
18. Fry A, Littlejohns TJ, Sudlow C, Doherty N, Adamska L, Sprosen T, Collins R, Allen NE (2017) Comparison of sociodemographic and health-related characteristics of UK Biobank participants with those of the general population. Am J Epidemiol 186(9):1026-1034

19. Adams M, Hill WD, Howard DM, Davis KA, Deary IJ, Hotopf M, McIntosh AM (2021) Factors associated with sharing email information and mental health survey participation in two large population cohorts. Int J EpidemiolA 49(2):410-421

20. Davis KAS, Coleman JRI, Adams M, Allen N, Breen G, Cullen B, Dickens C, Fox E, Graham N, Holliday J, Howard LM, John A, Lee W, McCabe R, McIntosh A, Pearsall R, Smith DJ, Sudlow C, Ward J, Zammit S, Hotopf M (2020) Mental health in UK Biobank: development, implementation and results from an online questionnaire completed by 157366 participants: a reanalysis. BJPsych Open 6(2):1-8

21. Glaesmer H, Schulz A, Häuser W, Freyberger HJ, Brähler E, Grabe H-J (2013) The childhood trauma screener (CTS)-development and validation of cut-off-scores for classificatory diagnostics. Psychiatr Prax 40(4):220-226

22. Kroenke K, Spitzer RL, Williams JB, Löwe B (2010) The patient health questionnaire somatic, anxiety, and depressive symptom scales: a systematic review. Gen Hosp Psychiatry 32(4):345-359

23. Spitzer RL, Kroenke K, Williams JB, Löwe B (2006) A brief measure for assessing generalized anxiety disorder: The GAD-7. Arch Intern Med 166(10):1092-1097

24. Saunders JB, Aasland OG, Babor TF, De la Fuente JR, Grant M (1993) Development of the alcohol use disorders identification test (AUDIT): WHO collaborative project on early detection of persons with harmful alcohol consumption-II. Addiction 88(6):791-804

25. McGrath JJ, Saha S, Al-Hamzawi A, Alonso J, Bromet EJ, Bruffaerts R, Caldas-de-Almeida JM, Chiu WT, de Jonge P, Fayyad J (2015) Psychotic experiences in the general population: A crossnational analysis based on 31261 respondents from 18 countries. JAMA Psychiat 72(7):697-705

26. Grabe HJ, Schulz A, Schmidt CO, Appel K, Driessen M, Wingenfeld K, Barnow S, Spitzer C, John U, Berger K, Wersching H (2012) A brief instrument for the assessment of childhood abuse and neglect: the childhood trauma screener (CTS). Psychiatrische Praxis 39(3):109-115

27. American Psychiatric Association, DSM-5 Task Force (2013) Diagnostic and statistical manual of mental disorders: DSM-5, 5th edn. American Psychiatric Publishing Inc, Arlington

28. Frissa S, Hatch SL, Fear NT, Dorrington S, Goodwin L, Hotopf M (2016) Challenges in the retrospective assessment of trauma: comparing a checklist approach to a single item trauma experience screening question. BMC Psychiatry 16(1):20

29. Khalifeh H, Oram S, Trevillion K, Johnson S, Howard LM (2015) Recent intimate partner violence among people with chronic mental illness: findings from a national cross-sectional survey. Br J Psychiatry 207(3):207-212

30. Collins LM, Lanza ST (2010) Latent class and latent transition analysis. John Wiley \& Sons, Hoboken

31. Schwarz G (1978) Estimating the dimension of a model. Ann Stat 6(1):461-464

32. Sclove SL (1987) Application of model-selection criteria to some problems in multivariate analysis. Psychometrika 52(3):333-343

33. Linzer DA, Lewis JB (2011) poLCA: an R package for polytomous variable latent class analysis. J Stat Softw 42(10):1-29

34. Bozdogan H (1987) Model selection and Akaike's information criterion (AIC): the general theory and its analytical extensions. Psychometrika 52(3):345-370

35. Ramaswamy V, DeSarbo WS, Reibstein DJ, Robinson WT (1993) An empirical pooling approach for estimating marketing mix elasticities with PIMS data. Mark Sci 12(1):103-124
36. R Development Core Team (2010) R: A Language and Environment for Statistical Computing v. 3.3.2. https://www.r-project.org/

37. Office for National Statistics (2016) Abuse during childhood: Findings from the Crime Survey for England and Wales, year ending March 2016. Office for National Statistics, London

38. Radford L, Corral S, Bradley C, Fisher H, Bassett C, Howat N, Collishaw S (2011) Child abuse and neglect in the UK today. NSPCC, London

39. Office for National Statistics (2018) Domestic abuse: findings from the Crime Survey for England and Wales: year ending March 2018. Office for National Statistics, London

40. Benjet C, Bromet E, Karam E, Kessler R, McLaughlin K, Ruscio A, Shahly V, Stein DJ, Petukhova M, Hill E (2016) The epidemiology of traumatic event exposure worldwide: results from the World Mental Health Survey Consortium. Psychol Med 46(2):327-343

41. Khalifeh H, Hargreaves J, Howard LM, Birdthistle I (2013) Intimate partner violence and socioeconomic deprivation in England: findings from a national cross-sectional survey. Am J Public Health 103(3):462-472

42. Blunt D (2011) Analysis of the 2010/11 British Crime Survey intimate personal violence split-sample experiment Home Office Methodology Report. Home Office, London

43. McAnee G, Shevlin M, Murphy J, Houston J (2019) Where are all the males? Gender-specific typologies of childhood adversity based on a large community sample. Child Abuse Negl 90:149-159

44. Office for National Statistics (2018) Sexual offences in England and Wales: year ending March 2017. Office for National Statistics, London

45. Desai S, Arias I, Thompson MP, Basile KC (2002) Childhood victimization and subsequent adult revictimization assessed in a nationally representative sample of women and men. Violence Vict 17(6):639-653

46. Scott S, Williams J, McNaughton Nicholls C, McManus S, Brown A, Harvey S, Kelly L, Lovett J (2015) Violence, abuse and mental health in England: population patterns. Responding Effectively to Violence and Abuse (REVA project) Briefing 1. DMSS, NatCen, CWASU, \& Truth, London

47. Devries KM, Child JC, Bacchus LJ, Mak J, Falder G, Graham $\mathrm{K}$, Watts C, Heise L (2014) Intimate partner violence victimization and alcohol consumption in women: A systematic review and meta-analysis. Addiction 109(3):379-391

48. Morgan C, Reininghaus U, Reichenberg A, Frissa S, SELCoH Study Team, Hotopf M, Hatch SL (2014) Adversity, cannabis use and psychotic experiences: evidence of cumulative and synergistic effects. Br J Psychiatry 204(5):346-353

49. Christie C (2018) A Trauma-informed health and care approach for responding to child sexual abuse and exploitation: current knowledge report. Department of Health and Social Care, London

50. NICE (2014) Domestic violence and abuse: multi-agency working. Public health guideline [PH50]. National Institute for Health and Care Excellence, London

51. Khalifeh H, Moran P, Borschmann R, Dean K, Hart C, Hogg J, Osborn D, Johnson S, Howard L (2015) Domestic and sexual violence against patients with severe mental illness. Psychol Med 45(04):875-886

52. Read J, Harper D, Tucker I, Kennedy A (2018) Do adult mental health services identify childabuse and neglect? A systematic review. Int J Ment Health Nurs 27:7-19. https://doi.org/10.1111/ inm. 12369

53. (REVA) REtVaA, (2015) A briefing for mental health professionals: why asking about abuse matters to service users. Child and Woman Abuse Studies Unit, London 
54. Hughes E, Lucock M, Brooker C (2019) Sexual Violence and Mental Health Services: A Call to Action. Epidemiol Psychiatr Sci. https://doi.org/10.1017/S2045796019000040

55. Batty GD, Gale CR, Kivimäki M, Deary IJ, Bell S (2020) Comparison of risk factor associations in UK Biobank against representative, general population based studies with conventional response rates: prospective cohort study and individual participant meta-analysis. BMJ. https://doi.org/10.1136/bmj.m131

56. Armour C, Elhai JD, Layne CM, Shevlin M, Duraković-Belko E, Djapo N, Pynoos RS (2011) Gender differences in the factor structure of posttraumatic stress disorder symptoms in warexposed adolescents. J Anxiety Disord 25(4):604-611

57. McChesney GC, Adamson G, Shevlin M (2015) A latent class analysis of trauma based on a nationally representative sample of US adolescents. Soc Psychiatry Psychiatr Epidemiol 50(8):1207-1217

58. World Health Organization (2021) Fact sheet: violence against women. WHO, Geneva 